\title{
Juridicidade do Dano Ambiental: gestão da zona costeira e aspectos da exploração do pré-sal pelo Brasil
}

\author{
José Rubens Morato Leite ${ }^{1}$ \\ Leonio José Alves da Silva ${ }^{2}$
}

\begin{abstract}
Resumo: O presente texto objetiva comentar a condução do processo brasileiro de exploração do petróleo na região do Pré-Sal e a aplicação da teoria da sociedade de risco desenvolvida por Ulrich Beck em 1986 na Alemanha, abordando a mundialização dos problemas ecológicos, a crise ambiental, a juridicidade do dano ambiental, as características da responsabilidade civil de longa duração, normas de prospecção petrolífera e seus impactos sobre a gestão da Zona Costeira do Brasil e o modelo de exploração, além dos prováveis vícios da Portaria MMA n. 422/2011. A pesquisa partiu de uma revisão de literatura e da análise de normas, notadamente a Portaria MMA n. $422 / 2011$. Serão cotejadas as normas de prospecção frente aos princípios ambientais, mormente o da precaução, além de julgados sobre a responsabilização nos acidentes com a perfuração, transporte e armazenamento do petróleo no Brasil.
\end{abstract}

Palavras-chave: Dano ambiental. Gestão da Zona Costeira. Exploração do Pré-Sal.

\begin{abstract}
This text aims to comment on the leading of the Brazilian process of oil exploration in the region of Subsalt and the application of risk society theory, developed by Ulrich Beck in 1986 in Germany, addressing the globalization of ecological problems, the environmental crisis, legalizes of environmental damage, the characteristics of long-term liability rules for oil prospecting and its impacts on the management of the coastal area of Brazil and the model of exploitation, in addition to the likely vices of the Ordinance MMA n. 422/2011. The survey came from a literature review and analysis of norms, notably the Ordinance MMA n. $422 / 2011$. The prospecting norms will be confronted with environmental principles, especially the precaution, in addition to judgements on accountability in accidents with the drilling, transportation and storage of oil in Brazil.
\end{abstract}

Key words: Environmental damage. Coastal zone management. Subsalt exploitation.

1 Possui Pós-doutorado em Direito pela Macquarie Universtiy (Austrália). Doutor em Direito Ambiental pela Universidade Federal de Santa Catarina (UFSC). Professor Associado II dos Cursos de Graduação e Pós-Graduação em Direito da UFSC. Coordenador do Grupo de Pesquisa Direito Ambiental e Ecologia Política na Sociedade de Risco - DGP/CNPq. E-mail: moratoleite@yahoo.com.br.

2 Possui Pós-doutorado em Direito pela Universidade Federal de Santa Catarina (UFSC). Doutor em Direito pela Universidade Federal de Pernambuco (UFPE). Professor Colaborador de Direito Ambiental da UFPE. Coordenador do Grupo de Pesquisa Tutela dos Interesses Difusos - DGP/CNPq.E-mail: leonioalves@bol.com.br.

Recebido em: 28/11/2011.

Revisado em: 17/04/2012.

Aprovado em: 11/07/2012. 


\section{Introdução}

No presente estudo será realizada uma breve análise das bases da sociedade de risco e a exploração dos recursos naturais na região do Pré-Sal na costa brasileira, abordando a mundialização dos problemas ecológicos, a crise ambiental, a juridicidade do dano ambiental, as características da responsabilidade civil de longa duração, as normas de prospecção petrolífera e seus impactos sobre a gestão da Zona Costeira do Brasil e o modelo açodado de exploração, além dos prováveis vícios e incoerências da recente Portaria do Ministério do Meio Ambiente n. 422/2011, que alterou o procedimento administrativo de licenciamento ambiental na matéria. Preocupam a pressa e a massificação conferida ao modelo de licenciamento, além da ausência de debates científicos públicos a respeito da concessão exploratória (partilha) e diminuição das desigualdades regionais, além da observância, ou não, dos princípios ambientais.

Entre a exploração do Pré-Sal e a situação da usina hidrelétrica de Belo Monte, há muitas semelhanças, guardadas as proporções, em que: a) a sociedade não foi consultada (inclusive por exigência constitucional quanto às comunidades indígenas no entorno da hidrelétrica); b) a condução dos projetos legislativos aproxima-se única e exclusivamente de um viés econômico (a quem interessa diretamente a construção de um empreendimento imensamente impactante e as reais medidas de sua repercussão socioambiental?) e c) uma questionável propaganda verde difundida.

De igual modo, a ausência do diálogo com a sociedade incomoda, não apenas pelos reclames constitucionais da publicidade, da transparência, da eficiência e da participação popular no trato das questões ambientais, mas, primordialmente, pela nítida exclusão do sadio envolvimento e esclarecimento da população, ao ponto da aprovação de parecer legislativo, referente ao PLS n. 448/2011, no âmbito do Senado Federal, em 19 de outubro de 2011, ser considerada situação consolidada. ${ }^{3}$

Mais detalhes sobre o processo legislativo acessar: <http://www.senado.gov.br/ noticias/agencia>. Acesso em: 24 out. 2011. 


\section{Sociedade de Risco e Crise Ambiental}

Em 1986, o sociólogo alemão Ulrich Beck (2010, p. 30) produziu a obra Sociedade de risco, um livro que deve ser considerado como divisor no entendimento dos impactos causados pelo processo de industrialização em todos os continentes, leitura indispensável à compreensão dos antecedentes, fenômenos concomitantes e coadjuvantes na transformação das sociedades produtoras em sociedades consumidoras e a falta de preparo dos países para conviver com uma realidade desafiadora.

Trabalhando com um enfoque multidisciplinar (sociológico, antropológico, econômico, jurídico, matemático, geográfico, médico, físico-químico e de outras visões), Beck descortina um olhar singular sobre os problemas que assolam a nova sociedade massificada, que consome pela satisfação psíquica, degrada o ambiente sem o sentimento de culpa, explora recursos em progressão infinitamente superior à capacidade de regeneração e fomenta a produção de uma infindável cadeia de riscos em atividades do cotidiano, antes inimagináveis no modelo de produção clássica, sem a presença do fator lucro.

Chama atenção para a ausência de estamentos, a negação do risco, a dissimulação do medo, a convivência arrogante com a legitimação da ignorância e a imposição de um modelo de percepção exclusivamente predatório dos recursos naturais, diante das novas "necessidades" (DERANI, 2008, p. 152-153) impostas pela avassaladora publicidade mundializada.

Destaca, ainda, a transformação dos modelos sociais e seus parâmetros: a inserção da mulher no mercado de trabalho e a modificação de posições no nicho familiar, as oscilações das pirâmides geográficas e a reabertura do incômodo debate malthusiano, a incorporação de um modo de produção e cultura universais, com a negação dos modos locais de identidade, a proliferação dos fatores de risco na indústria, no campo, no processo desordenado de urbanização (planificado em poucas cidades na Europa e Américas do Norte e Central) e outros fenômenos típicos do pós-industrialismo. 
Outros tópicos de sua magistral obra consistem no empobrecimento civilizacional (pauperização), na irresponsabilidade organizada e em outra ótica sobre a teoria do risco na construção do debate sociológico. A obra registra, ainda, o fenômeno cíclico dos riscos no contexto internacional, na qual analisa o efeito bumerangue (BECK, 2010, p. 44) das externalidades na sociedade moderna, deixando claro que a produção dos riscos ocorre em escala mundial e seus criadores tendem a ignorar que os efeitos negativos, de qualquer técnica ou produto inserido no mercado, retornam direta ou indiretamente para os criadores, encerrando um caminho de destruição inversa.

Talvez, um dos pontos de maior relevo na leitura da Sociedade de risco, tarefa dificílima em virtude da plenitude e da atualidade do estudo, encontra-se na inclusão do risco na gestão financeira das empresas, quando se constata que a cadeia produtiva não ignora o risco, mas, inversamente, mascara-o no ciclo de fabricação e o dissemina de modo imperceptível diante do consumidor massificado, represado na própria necessidade de sobrevivência ou manutenção de um falacioso padrão social.

A sociedade de risco, longe de construir uma apologia ao terror e ao fatalismo tecnológico, adverte sobre as consequências indesejáveis e insanáveis, em sua maior parte, do culto ao consumo exacerbado, da concepção agressiva e insustentável dos recursos naturais como bens de apropriação temporal e descartáveis e toda a gama de condutas incompatíveis com o compromisso intergeracional preconizado na disciplina ambiental.

Assim, a crise ambiental, como consequência de um modelo de exploração que enxerga apenas uma das faces do binário ético-ambiental, consubstanciado na ausência de freios morais, concebendo a natureza como recurso (caráter econômico/meio para alcançar metas/lucro) e afastando a visão de santuário (fonte de sobrevivência e integração dos seres em relação de absoluta igualdade), deflagrou o maior e mais preocupante dilema das últimas décadas: temos o direito de representar os seus anseios das futuras gerações no presente?

Ou, de forma mais direta e percuciente: as escolhas hoje realizadas poderão ser revertidas pelas sociedades do futuro? No cerne do debate 
sobre a crise ambiental, ressaltam-se: a) a carência de alimentos e água para a população mundial (7.000.000.000 habitantes em 31/10/2011, consoante estimativas do relatório elaborado pela ONU), ${ }^{4}$ aliada ao desmedido desperdício de milhares de toneladas diárias; b) a demanda de fontes energéticas renováveis; c) mudança de padrões de vida, com a redução urgente dos níveis de consumo irresponsáveis e insustentáveis (consumo pelo consumo no vazio ético da sociedade pós-industrial); e d) o despertar ecológico para a consciência de finito do patrimônio ambiental, em todas as suas dimensões, com especial destaque para o acervo natural.

Mais uma vez, o dilema entre tecnologia e ética é trazido à tona, demandando uma postura transparente de nossa opção em preservar, poupar, educar ou destruir, desperdiçar ou ignorar os problemas e as reais necessidades; infelizmente, na passagem dos séculos XX para o XXI, a escolha da maior parte dos blocos econômicos foi a primeira alternativa. Não se pode reduzir a complexidade ambiental e muito menos traduzi-la na expressão do lucro, mas, certamente, tal fenômeno econômico, conhecido pelo homo faber é um dos principais responsáveis pelo hiato entre aparato tecnológico e distribuição de riquezas e redução das desigualdades sociais: técnica e volúpia pelo lucro selam acordo em um polo e, em outro, diametralmente oposto, encontram-se as reais necessidades dos seres vivos e a perspectiva de sustentabilidade.

Outro fato da sociedade de risco, a merecer maior reflexão, encontra-se na vertiginosa ascensão dos fatores potenciais de risco na sociedade hodierna: cada tecnologia empregada exige a valoração e o aprofundamento dos riscos criados; contudo, a busca de resultados não permite considerar o perigo, passando o criador a ignorá-lo embutindo seus custos na escala produtiva.

Em torno de tais premissas (consumo desenfreado, desperdício, ausência de ética para reconhecer limites à exploração dos recursos naturais, falta de investimento em fontes renováveis de energia e descompromisso com a educação ambiental), alicerçam-se os significativos exemplos de

4 Relatório sobre a situação da população mundial - 2011. Disponível em: <http://www. oi.acidi.gov.pt>. Acesso em: 24 out. 2011. 
tal desordem, dentre os quais, ressaltam-se significativos acidentes ambientais dos últimos tempos.

A sociedade de risco é pródiga de eventos transfronteiriços, como: a) o acidente com a usina nuclear de Chernobyl (1986); b) a bomba de Césio 137 em Goiânia (1987); c) o vazamento do Petroleiro Exxon Valdez (1989); d) a encefalopatia espongiforme bovina (EEB) ou Bovine Spongiforme Encephalopaty (BSE) (1986-2004), registrada na contaminação da carne bovina derivada de animais alimentados industrialmente com ração contaminada na Europa; e) a escalada dos vírus "Ebola" (1976) e "H1N1" (tipologia próxima dos casos da "gripe espanhola" em 1918 e na pandemia de 2009); f) atentados terroristas; g) acidentes com a plataforma petrolífera P36 da Petrobras; h) o desastre do Golfo do México (2010); e i) a explosão da usina nuclear de Fukushima (2011) etc.

No vazamento ocorrido no Golfo do México, com a explosão e afundamento da plataforma Deepwater Horizon, da British Petroleum Co., em abril de 2010, um cálculo de 5.000.000 de barris por todo o período foi estimado; entretanto, estudos posteriores acresceram tal número. ${ }^{5}$ Após a explosão, implantou-se uma série de medidas para tentar minimizar os impactos ambientais, consistentes na contenção parcial com diques de flotação, utilização de substâncias dispersantes, bombeamento por dutos e cápsulas submarinas, represamento do fogo e a queima do óleo derramado, formando fumaça altamente tóxica; contudo, os danos oriundos de tal episódio atingiram não apenas a costa dos Estados Unidos, bem como alcançaram águas externas ao Golfo do México e prejudicaram a vida de espécies selvagens em reservas dos Estados do Sul norte-americano.

Das principais consequências do acidente com a plataforma petrolífera no Golfo do México, registra-se a fragilidade dos sistemas de segurança envolvidos e a inadequação e insuficiência dos mecanismos preventivos/precaucionais e o alastramento da danosidade.

Catástrofe ambiental também foi registrada com o navio tanque Prestige, de 243 metros, em 13 de novembro de 2002, transportando

5 Disponível em: <http://geography.about.com/od/lists/a/largestoilspills.htm>. Acesso em: 30 out. 2011. 
77.000 toneladas de óleo, ao sofrer um rombo em seu caso nas imediações do Cabo Finisterra e afundar em 19 de novembro daquele ano, em torno de $240 \mathrm{~km}$ da costa Oeste da cidade de Vigo (Espanha).

Uma operação de emergência foi ativada, contando com o Instituto Hidrográfico da Espanha e o Gabinete de Relações Públicas, utilizando-se o modelo de acompanhamento por deriva e mapeamento via satélite, com quatro sistemas flutuantes lançados no local do acidente e aplicação dos recursos HOPS (Harvard Operational Prediction Survey) e SWAN (Simulating Waves Nearshore), com técnicas meteorológicas da Marinha dos Estados Unidos e outros centros europeus de meteorologia. ${ }^{6}$

A sociedade de risco congrega, dentre as diferentes características, a capacidade de causar danos transfronteiriços e com múltipla nacionalidade, não mais restritos aos limites geográficos de um país ou continente, situação comum nas hipóteses de derramamento de óleo, contaminação por vírus e bactérias, acidentes nucleares com explosão de reatores ou contaminação do solo, ar e água, ambientes virtuais (transferência irregular de tecnologia e dados), veiculação de doenças por alimentos, transporte de animais, "importação" de resíduos (prática ainda utilizada pelos Estados Unidos e países europeus na remessa de lixo hospitalar, radioativo e orgânico para os países do continente europeu e América do Sul).

Outro traço distintivo da sociedade de risco consiste na produção de danos transtemporais ou atemporais, insusceptíveis de apresamento em um momento temporal, produzindo efeitos por décadas ou séculos além da época em que ocorreram, constituindo exemplos: a contaminação por radioisótopos (acidente de Chernobyl e Goiânia), a contaminação do solo e dos lençóis freáticos com gases e metais pesados, oriundos dos lixões, prática apenas combatida com a regulamentação da Política Nacional dos Resíduos Sólidos (Lei n. 12.305 /2010) e o respectivo sistema de monitoramento, a poluição marítima atingindo várias gerações e prejudicando a cadeia reprodutiva marítima, enfim, todos os casos em que ocorra a continuidade de efeitos e externalidades para além do cenário temporal no qual foram originados. Diante de tais marcas, como assegurar efetivi-

6 Disponível em: <http://www.guardian.co.uk/gall/0,8542,842603,00.html>. Acesso em: 24 out. 2011. 
dade à proteção ambiental de bens extremamente sensíveis e integrantes de um acervo difuso, destinado às gerações de hoje e do amanhã?

O acidente com a usina de Fukushima, no Japão, o desastre com o navio tanque Prestige, na costa da Espanha, a explosão da plataforma petrolífera no Golfo do México, no eixo Sul dos Estados Unidos e outros eventos, desconhecidos da grande mídia, têm efeitos comuns na contaminação das Zonas Costeiras, no transporte do lixo marítimo transnacional, na alteração climática e, em larga escala, o assombroso problema dos refugiados ambientais (tema ainda em construção doutrinária e alvo de pouca regulamentação internacional que extrapola o âmbito de competência interna dos países).

\section{Juridicidade da Danosidade Ambiental no Brasil: perfil e ca- racterísticas}

A compreensão do dano ambiental e sua recepção pelos diversos sistemas normativos deve ser estudada nas duas grandes gerações de problemas ambientais, a saber: a) os problemas ambientais de primeira geração: vinculados ao surgimento da poluição, em suas diferentes formas, sua prevenção e controle das causas e efeitos, além da defesa do direito fundamental ao meio ambiente; e b) os problemas ambientais de segunda geração: abrangendo os efeitos duradouros no tempo e no espaço da degradação ambiental, noção forjada em uma sensitividade ecológica sistêmica e cientificamente ancorada, indispensável para o enfrentamento do problema, consoante leciona Canotilho (2001, p. 21-25).

$\mathrm{O}$ direito ambiental agrega crescentemente conhecimentos multidisciplinares, convocando saberes anteriormente inconciliáveis e, hodiernamente, indissociáveis; tal transição sistêmica de pensamento ou saberes guarda íntima relação com a transformação do conceito de ética natural e sua incompatibilidade com o modelo econômico ainda dominante que despreza um conteúdo ecológico mínimo e essencial à sobrevida na terra (WINTER, 2009, p. 4), acentuando vertiginosamente os problemas intergeracionais; assim, o dano ambiental na sociedade brasileira decorre de fatores complexos e, ao mesmo tempo, previsíveis em uma recente escala 
histórica cada vez mais relativizada, onde os séculos passam a compor uma fração de minutos na marcha de devastação da natureza e pauperização dos recursos naturais, requerendo um novo olhar para a tutela dos bens jurídicos emergentes: a otimização e o combate ao desperdício e o freio do consumo irresponsável, moldado em um esquema de atuação em rede, com valores e práticas e planejamentos convergentes, típicos do pluralismo legal global.

De difícil mensuração, constatação e determinação de sua origem, notadamente nas questões que envolvam prejuízo direto ao patrimônio natural, o dano ambiental encontra elementos propulsores da sua ocorrência na ausência de planejamento, na ineficiência administrativa em aplicar os princípios da prevenção e precaução, na banalização dos problemas ambientais como decorrentes das externalidades econômicas, na adoção de modelos sociais e de concepções de natureza exclusivamente produtiva (o patrimônio ambiental teria finalidade estritamente de reposição de recursos), o enfraquecimento da ideia preservacionista, com a negação de uma sustentabilidade forte (WINTER, 2009, p. 1-2) (responsável pelo controle da exploração abaixo dos limites de taxas de produção e a gradativa substituição dos recursos não renováveis pelos renováveis) e incorporação das entropias.

Sendo o dano ambiental um fenômeno distante da clássica teoria da causalidade, ele apresenta características exclusivas dos direitos difusos (LEITE, 2010, p. 95-116), como a difícil determinação, a indivisibilidade, a inalienabilidade, a imprescritibilidade, a indisponibilidade e a afetação intergeracional, além de um campo de atuação transfronteiriço, exigindo de todos os Estados a elaboração de mecanismos internacionais de cooperação e de controle. Assim como o Fundo Nacional de Defesa dos Direitos Difuso, instituído no artigo 13, da Lei n. 7.347/1985 e regulamentado pela Lei n. 9.008/1995 e Decreto posterior, seria proveitosa a criação de um Fundo Internacional de Proteção Ambiental, capaz de minimizar ações negativas sobre o meio e de aplicar recursos em condutas precaucionais e preventivas, substituindo a tradicional feição reparadora repressiva por um novo modelo de cooperação entre os países e de securitização internacional. 
Outro dado complementar é a proibição do retrocesso social (PRUDENTE, 2010. p. 38) em questões de natureza difusa, seja na seara ambiental, ou em outros campos de interesse público, como preservação das situações protetivas consolidadas, sempre objetivando maiores garantias dos que as realizadas e partindo da premissa de que se está em notória defasagem pelo passivo ambiental gerado durante séculos de devastação.

\begin{tabular}{|l|l|}
\hline \multicolumn{2}{|c|}{ Paradoxos da Juridicidade do Dano Ambiental } \\
\hline À pessoa ou aos seus bens & \multicolumn{1}{c|}{ Dano Ambiental } \\
\hline Pessoalidade & Dano puro ou reflexo \\
\hline Certeza & Impessoalidade: difuso \\
\hline Atualidade & Incerteza \\
\hline Subsistência & Futuro, eventual \\
\hline Anormalidade & Gradativo: causas/efeitos \\
\hline Nexo de causalidade definido & Anormalidade: tolerância social \\
\hline Prescrição dos direitos interindividuais & Nexo de causalidade pode ser indefinido \\
\hline Dano moral intersubjetivo & Imprescritibilidade do dano difuso \\
\hline Prova do dano & Dano moral ambiental: valores diferenciados \\
\hline Bens e direitos intersubjetivos & Prova indiciária \\
\hline $\begin{array}{l}\text { Direito adquirido e estabilidade do ato jurí- } \\
\text { dico }\end{array}$ & $\begin{array}{l}\text { Quem danifica indeniza, mesmo com licença } \\
\text { (Prevenção, precaução e poluidor pagador e re- } \\
\text { parador do dano) }\end{array}$ \\
\hline
\end{tabular}

Quadro 1: Paradoxos da Juridicidade do Dano Ambiental

Fonte: Leite (2010, p. 99)

\section{Responsabilidade Civil de Longa Duração: dados internos e internacionais}

Em poucas décadas de aplicação do sistema ambiental brasileiro, percebe-se a necessidade de ruptura de modelos, de fórmulas e de formas de pensar a estrutura lógica da responsabilidade civil frente às necessidades da sociedade de risco.

O processo legislativo brasileiro de promoção aos direitos difusos foi lento e, por conseguinte, a formação de um acervo jurisprudencial difuso também acompanhou tal ritmo, ocasionando certo engessamento rompido apenas com a redemocratização e a aparição de normas jurídicas como a Lei da Ação Civil Pública (Lei n. 7.347/1985), a Constituição Fe- 
deral de 1988, o Código de Defesa do Consumidor (Lei n. 8.078/1990) e outros diplomas normativos de caráter especial.

A antiga e clássica estrutura de responsabilização (fundada no dogma da culpa) não suportou a velocidade dos fatos vivenciados na sociedade de risco e uma reformulação de ideias ainda é imperiosa, admitindo a defasagem estrutural do modelo de responsabilização repressivo, cuja causalidade seria um fenômeno estanque e sua consequente flexibilização, tanto no âmbito interno quanto no internacional, pois o risco não possui fronteiras e muito menos nacionalidade.

Na sociedade de risco se está diante de uma potencialidade de lesão ou de lesão indiscriminada, dispersa no mundo, sem fronteiras ou subordinação a estratos sociais, balizas temporais, forjada na dúvida; no âmbito internacional, após inúmeros desastres e proporções continentais, um desenho de responsabilidade civil de longa duração (CANOTILHO, 2011, p. 26) é formulado, alcançando as gerações do futuro e adotando mecanismos preventivos e precaucionais, exigindo justificativas sociais adequadas e o emprego da melhor tecnologia possível (BAT - Best Available Technology), além de uma política dissuasiva, fomentando o surgimento de uma Responsabilidade Civil Internacional, na qual se destacam a Convenção das Nações Unidas sobre o Direito do Mar (1982), a Convenção Internacional sobre Responsabilidade Civil por danos da poluição marítima (1969 e 1973/1978), (envolvendo a prospecção, o transporte, o armazenamento do petróleo, derivados e lixo marítimo), a Convenção Internacional sobre Preparo e Cooperação nos casos de poluição por derramamento de óleo (OPRC/1990) e, em complemento, as Leis Federais n. 9.478/1997, n. 9.966/2000 (regulamentada pelo Decreto n. 4.136/2002) e n. $12.351 / 2010$.

De igual modo, a doutrina do risco precisa ser francamente recepcionada no Direito e nas decisões judiciais, reconhecendo sua imprescindibilidade para o porvir (tutela intergeracional) e a insuficiência da moldura de responsabilidade proposta pela Teoria Geral do Direito Civil, arrimada na tripla perspectiva da conduta, da causalidade certa, exaustivamente provada, e do evento danoso certo; enfim, uma nova concepção 


\section{da defesa do patrimônio coletivo precisa ser efetivada no Brasil, consoli- dando o direito ao futuro como garantia fundamental.}

\begin{tabular}{|c|c|}
\hline Período & Evento \\
\hline $03 / 1975$ & $\begin{array}{l}\text { Um cargueiro fretado pela Petrobras derrama } 6 \text { mil toneladas de óleo na Baía da } \\
\text { Guanabara. }\end{array}$ \\
\hline $10 / 1983$ & 3 milhões de litros de óleo vazam de um oleoduto da Petrobras em Bertioga. \\
\hline $02 / 1984$ & $\begin{array}{l}93 \text { mortes e } 2.500 \text { desabrigados na explosão de um duto da Petrobrás na favela } \\
\text { Vila Socó, Cubatão (SP). }\end{array}$ \\
\hline $08 / 1984$ & Gás vaza do poço submarino de Enchova (Petrobras): 37 mortos e 19 feridos. \\
\hline $05 / 1994$ & 2,7 milhões de litros de óleo poluem 18 praias do litoral norte paulista. \\
\hline $03 / 1997$ & $\begin{array}{l}\text { O rompimento de um duto da Petrobrás que liga a Refinaria de Duque de Caxias } \\
\text { (RJ) ao terminal DSTE-Ilha D'Água provoca o vazamento de } 2,8 \text { milhões de litros } \\
\text { de óleo combustível em manguezais na Baía de Guanabara (RJ). }\end{array}$ \\
\hline 13/10/1998 & $\begin{array}{l}\text { Uma rachadura de cerca de um metro que liga a refinaria de São José dos Campos } \\
\text { ao Terminal de Guararema, ambos em São Paulo, causa o vazamento de 1,5 mi- } \\
\text { lhões de litros de óleo combustível no rio Alambari. O duto estava há cinco anos } \\
\text { sem manutenção. }\end{array}$ \\
\hline $18 / 01 / 2000$ & $\begin{array}{l}\text { O rompimento de um duto da Petrobras que liga a Refinaria Duque de Caxias ao } \\
\text { terminal da Ilha d'Água provocou o vazamento de } 1,3 \text { milhão de litros de óleo } \\
\text { combustível na Baía da Guanabara. A mancha se espalhou por } 40 \text { quilômetros qua- } \\
\text { drados. Laudo da Coppe/UFRJ, divulgado em } 30 \text { de março, concluiu que o derra- } \\
\text { me de óleo foi causado por negligência da Petrobras, já que as especificações do } \\
\text { projeto original do duto não foram cumpridas. }\end{array}$ \\
\hline $16 / 07 / 2000$ & $\begin{array}{l}\text { Quatro milhões de litros de óleo foram despejados nos rios Barigüi e Iguaçu, no } \\
\text { Paraná, por causa de uma ruptura da junta de expansão de uma tubulação da Refi- } \\
\text { naria Presidente Getúlio Vargas (Repar - Petrobras). O acidente levou duas horas } \\
\text { para ser detectado, tornando-se o maior desastre ambiental provocado pela Petro- } \\
\text { bras em } 25 \text { anos. }\end{array}$ \\
\hline $01 / 2001$ & $\begin{array}{l}\text { Um acidente com o Navio Jéssica causou o vazamento de mais de } 150 \text { mil barris } \\
\text { de combustível no Arquipélago de Galápagos. }\end{array}$ \\
\hline $16 / 02 / 2001$ & $\begin{array}{l}\text { Rompe mais um duto da Petrobrás, vazando } 4.000 \text { mil litros de óleo diesel no Cór- } \\
\text { rego Caninana, afluente do Rio Nhundiaquara, um dos principais rios da região. } \\
\text { Este vazamento trouxe grandes danos para os manguezais da região, além de con- } \\
\text { taminar toda a flora e fauna. O Ibama proibiu a pesca até o mês de março. }\end{array}$ \\
\hline $11 / 08 / 2001$ & $\begin{array}{l}\text { Um vazamento de óleo atingiu } 30 \mathrm{~km} \text { nas praias do litoral norte baiano entre as } \\
\text { localidades de Buraquinho e o balneário da Costa do Sauípe. A origem do óleo é } \\
\text { árabe. }\end{array}$ \\
\hline $15 / 08 / 2001$ & $\begin{array}{l}\text { Vazamento causado por navios que despejam ilegalmente seus depósitos de óleo } \\
\text { atingiu mais de } 200 \text { pingüins, perto da costa da Argentina. }\end{array}$ \\
\hline 20/09/2001 & $\begin{array}{l}\text { Vazamento de gás natural da Estação Pitanga da Petrobras a } 46 \text { km de Salvador/ } \\
\text { Bahia atingiu uma área de } 150 \text { metros em um manguezal . }\end{array}$ \\
\hline
\end{tabular}




\begin{tabular}{|c|l|}
\hline Período & \multicolumn{1}{c|}{ Evento } \\
\hline $\mathbf{1 8 / 1 0 / 2 0 0 1}$ & $\begin{array}{l}\text { O navio petroleiro Norma que carregava nafta, da frota da Transpetro - subsidiário } \\
\text { da Petrobras, chocou-se em uma pedra na baía de Paranaguá, litoral paranaense, } \\
\text { vazando 392 mil litros do produto atingindo uma área de 3 mil metros quadrados. } \\
\text { O acidente culminou na morte de um mergulhador, Nereu Gouveia, de 57 anos, } \\
\text { que efetuou um mergulho para avaliar as condições do casco perfurado. }\end{array}$ \\
\hline $\mathbf{2 3 / 0 2 / 2 0 0 2}$ & $\begin{array}{l}\text { Cerca de 50 mil litros de óleo combustível vazaram do transatlântico inglês Caro- } \\
\text { nia, atracado no Pier da Praça Mauá, na Baía de Guanabara, Rio de Janeiro. O óleo } \\
\text { foi rapidamente contido. }\end{array}$ \\
\hline $\mathbf{1 2 / 0 6 / 2 0 0 2}$ & $\begin{array}{l}\text { Cerca de 450 toneladas de petróleo vazaram nesta quarta-feira na costa de Cin- } \\
\text { gapura em decorrência do choque entre um cargueiro tailandês e um petroleiro } \\
\text { cingapuriano. De acordo com a Autoridade Marítima e Portuária (MPA) de Cin- } \\
\text { gapura, o vazamento ocorreu quando um dos tanques do 'Neptank VII' se rompeu } \\
\text { durante a colisão. O acidente não deixou feridos. }\end{array}$ \\
\hline
\end{tabular}

Quadro 2: Alguns acidentes ambientais com o petróleo

Fonte: Ambiente Brasil (2011)

A recente trajetória dos desastres ecológicos envolvendo a atividade petrolífera aproxima-se da formatação de um novo modelo jurisprudencial no Brasil, qual seja: o reconhecimento das práticas preventivas e precaucionais no trato dos problemas ambientais, além da inversão do ônus da prova em matéria difusa e a instrumentalidade das ações coletivas como ferramentas decisivas no controle das políticas públicas e sua repercussão nos direitos difusos.

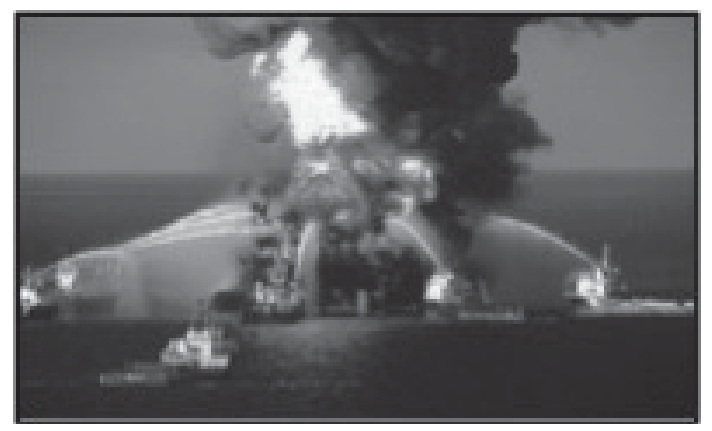

Figura 1: Explosão da plataforma Deepwater Horizon Fonte: Revista Veja (2012) 


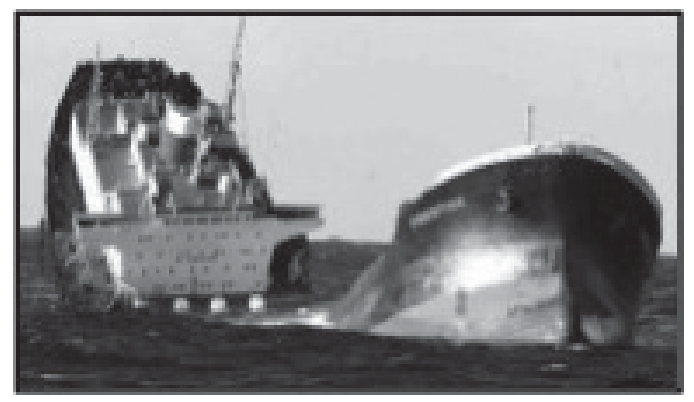

Figura 2: Afundamento do navio Prestige, em 19 de novembro de 2002 Fonte. Revista Veja (2012)

Dentre os vários julgados que ilustram a referida mudança de paradigmas, destacam-se os seguintes:

PROCESSUAL CIVIL E AMBIENTAL - AÇÃO CIVIL PÚBLICA - DANO AMBIENTAL - ADIANTAMENTO DE HONORÁRIOS PERICIAIS PELO PARQUET - MATÉRIA PREJUDICADA - INVERSÃO DO ÔNUS DA PROVA - ART. $6^{\circ}$, VIII, DA LEI 8.078/1990 C/C O ART. 21 DA LEI 7.347/1985 - PRINCÍPIO DA PRECAUÇÃO.

STJ. 2a Turma. RESP. 972.902/RS. Rel. Min. Eliana Calmon. DJ: 14/09/2009.

PROCESSUAL CIVIL E ADMINISTRATIVO. AMBIENTAL. AÇÃO CIVIL PÚBLICA. RESPONSABILIDADE POR DANO CAUSADO AO MEIO AMBIENTE. ZONA COSTEIRA. LEI 7.661/1988. CONSTRUÇÃO DE HOTEL EM ÁREA DE PROMONTÓRIO. NULIDADE DE AUTORIZAÇÃO OU LICENÇA URBANÍSTICO-AMBIENTAL. OBRA POTENCIALMENTE CAUSADORA DE SIGNIFICATIVA DEGRADAÇÃO DO MEIO AMBIENTE. ESTUDO PRÉVIO DE IMPACTO AMBIENTAL - EPIA E RELATÓRIO DE IMPACTO AMBIENTAL - RIMA. COMPETÊNCIA PARA O LICENCIAMENTO URBANÍSTICO-AMBIENTAL. PRINCÍPIO DO POLUIDOR-PAGADOR (ART. $4^{\circ}$, VII, PRIMEIRA PARTE, DA LEI 6.938/1981). RESPONSABILIDADE OBJETIVA (ART. 14, $\S 1^{\circ}$, DA LEI 6.938/1981). PRIN- 
CÍPIO DA MELHORIA DA QUALIDADE AMBIENTAL (ART. $2^{\circ}$, CAPUT, DA LEI 6.938/1981).

STJ. $2^{a}$ Turma. RESP. 769.753 Rel. Min. Herman Benjamin. DJ: 10/06/2011.

PROCESSUAL CIVIL. ADMINISTRATIVO. RECURSO ESPECIAL. DIVERGÊNCIA NÃO DEMONSTRADA. DANO AMBIENTAL. SANÇÃO ADMINISTRATIVA. IMPOSIÇÃO DE MULTA. AÇÃO ANULATÓRIA DE DÉBITO FISCAL. DERRAMAMENTO DE ÓLEO DE EMBARCAÇÃO DA PETROBRÁS. CERCEAMENTO DE DEFESA. REEXAME DE MATÉRIA PROBATÓRIA. SÚMULA 07/STJ. COMPETÊNCIA DOS ÓRGÃOS ESTADUAIS DE PROTEÇÃO AO MEIO AMBIENTE PARA IMPOR SANÇÕES. RESPONSABILIDADE OBJETIVA. LEGITIMIDADE DA EXAÇÃO.

STJ. $1^{\text {a }}$ Turma. RESP. 673.765 Rel. Min. Luiz Fux. DJ: 26/09/2005.

\section{Normas sobre a Exploração do Petróleo no Brasil}

A exploração petrolífera no Brasil está concentrada em duas fases de perfis distintos: a) fase do conhecimento e delineamento geomorfológico e de aquisição de dados sísmicos: nesta fase são realizados estudos e atividades de pesquisa do perfil geomorfológico na pretensa área a ser explorada; e b) a fase de instalação e prospecção propriamente dita: nesta fase encontra-se a atividade da extração (onshore ou terrestre e offshore ou marítima), do refino, do armazenamento e da comercialização, fincando-se o monopólio e muito posteriormente a regulação da atividade. (PALMA, 2011, p. 41-43)

Além das normas pertinentes à Responsabilidade ambiental por risco integral, integram o acervo legislativo as pertinentes à prospecção (Lei n. 9.478/1997, Resolução CONAMA 350/2004), abordando a indispensabilidade do Estudo Ambiental de Sísmica (EAS), do Relatório de Impacto Ambiental de Sísmica (RIAS), da Licença de Pesquisa Sísmica 
(LPS), do Plano de Controle Ambiental de Sísmica (PCAS), além da tramitação administrativa das respectivas licenças. ${ }^{7}$

Desde a realização das atividades sísmicas, o empreendedor gera impactos ambientais, com significativo relevo na biota marinha, ressaltando-se os de ordem física, sensorial, comportamental, crônica e indireta; contudo, tal fato não é divulgado perante a sociedade, como deveria ser advertido em sede de Audiência Pública prevista na Resolução CONAMA n. 350/2004.

Outros pontos preocupantes na atividade petrolífera brasileira são a autorização de exploração em APA (a exemplo da Resolução CONAMA n. 15/1993) ao permitir a operação de poços na APA de Piaçabuçu (AL) e o próprio transporte e fiscalização portuária (Lei n. 9.966/200) e os efeitos da exploração onshore nas comunidades locais.

Recentemente, em atenção ao processo de exploração petrolífera no Pré-sal e incremento de novos campos de extração, o Ministério do Meio Ambiente editou a Portaria MMA n. 422, de 26 de outubro de 2011, publicada no DOU de 28 de outubro de 2011, contemplando alterações no processo de licenciamento ambiental da prospecção e da produção petrolífera no ambiente marinho e na área de transição terra-mar.

Considerando a abrangência e o impacto da referida norma, questiona-se a pressa conferida abreviando-se o processo de licenciamento (uma vez que o Ministério do Meio Ambiente previu a hipótese de licenciamento em bloco ou por Processo Administrativo de Referência ou Processos Regionais) e o prejuízo com a falta de transparência diante da realização de audiências públicas não presenciais, como ressaltado em vários trechos da Portaria.

O licenciamento ambiental é marcado pela observância das peculiaridades de cada empreendimento potencialmente impactante, guarnecido por estudos prévios (normalmente específicos para cada ramo de atividade - no caso do petróleo, há previsão de modalidades únicas para o setor)

7 Decisão interessante sobre a abrangência e indispensabilidade do EAS e do RIAS, é possível encontrar no julgamento da Apelação Cível n. 2002.51.02.003634-1. TRF 2a Região. Rel. Des. Federal Poul Erik Drylund. DJ: 20/04/2010. 
e deve considerar as necessidades da "sede" de geração do risco; assim, admitindo a existência de um único processo de licenciamento para toda uma região, haveria um enfraquecimento ou esvaziamento do princípio constitucional da prevenção?

No artigo $3^{\circ}$, da Portaria MMA n. 422/2011, conceituam-se áreas, definem-se técnicas e instrumentos envolvidos no processo administrativo de licenciamento, destacando as Áreas de Sensibilidade Ambiental (ASA); Avaliação Ambiental de Área Sedimentar (AAAS) (diagnóstico socioambiental de área susceptível de exploração do petróleo e gás); Consultas públicas (instrumentos de publicidade dos atos de licenciamento, incluindo a ferramenta da audiência pública, que poderá ser realizada na modalidade não presencial); Estudo Ambiental de Área Sedimentar (EAAS); Estudo Ambiental de Perfuração (EAP); Estudo Ambiental de Sísmica (EAS); Estudo Ambiental de Teste de Longa Duração (EATLD); Ficha de Caracterização de Atividade (FCA) - documento apresentado pelo empreendedor, obedecendo ao modelo fornecido pelo IBAMA, na qual constam informações detalhadas sobre o empreendimento; Plano de Controle Ambiental de Sísmica (PCAS); Relatório em Linguagem Não Técnica (RLNT); Termo de Referência (TR); Teste de Longa Duração (TLD) e Zona de Transição terra-mar, compreendendo águas rasas e parte terrestre adjacente.

No procedimento, propriamente dito, destacam-se a abreviação de prazos e a possibilidade da concessão por empreendimentos em blocos, a exigência de Relatório em linguagem não técnica (art. $2^{\circ}, \mathrm{XII}$ ), aberta ao público não leigo e não especializado, além de prazos e distinção de áreas atingidas por possíveis impactos, merecendo especial crítica: a) nos artigos $2^{\circ}$, II e 22, da Portaria MMA n. 422/2011, admite-se a realização de consulta não presencial, inclusive na modalidade de audiência pública, apesar da obrigatoriedade da divulgação de dados sobre o licenciamento na internet (art. 21 da Portaria); b) nos artigo $7^{\circ}$, parágrafo único, artigo 12 , parágrafo único e artigo $18, \S 2^{\circ}$, cuida-se da presunção administrativa de prorrogação da LPS, LPP e LPTLD, respectivamente, se requeridas antes de 30 ou 120 dias do seu expirar, de acordo com o tipo, até a manifestação conclusiva do IBAMA e c) no artigo 20, a possibilidade do IBAMA instaurar Processo Administrativo de Referência para subsi- 
diar novos estudos, dispensando o detalhamento de dados, com a menção ao aludido processo e no artigo 23 , a centralização de empreendimentos em um único processo de licenciamento regional.

Duvidosa é a constitucionalidade da realização de audiências públicas não presenciais, cuja população não se faça ouvir diretamente, inclusive com a presença do representante do Ministério Público durante todo o ato, pois seria temerário admitir a oitiva à distância da comunidade diretamente atingida por eventual impacto resultante; assim, quando o Ministério do Meio Ambiente prevê tal possibilidade, coloca em risco a própria transparência do licenciamento ambiental; de igual modo, é altamente questionável a prorrogação presuntiva de uma licença ambiental pelo simples fato de inexistir pronunciamento conclusivo do órgão competente, após o protocolo tempestivo do pedido de prorrogação por parte do interessado.

Referida Portaria Ministerial cuida dos seguintes tipos de licenciamento: 


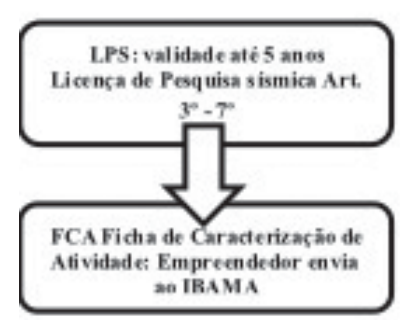

IBAMA dass ifica em classe I. classe 2 ou classe 3 , de acordo ram a nrafundid ade
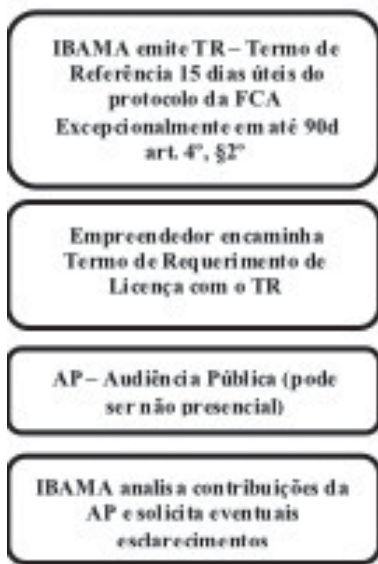

Empreendedor presta esdarecimentes $\mathrm{cm}$ at 64 meses da solicitaría

IBAMA publica parecer ef deferimento ou indeferimente da L.PS. Res posta em at 612 meses classe 1, 6 meses dasses 2.3

IBAMA pode auteriar pesquisas sismicas diretas nas situaçêes excluidas de Art. 10, I. $6.028 / 1081$

Praces do Art. $6^{\circ}$ pedem ser alterades com acordo entre IRAMA cemn revendeder.

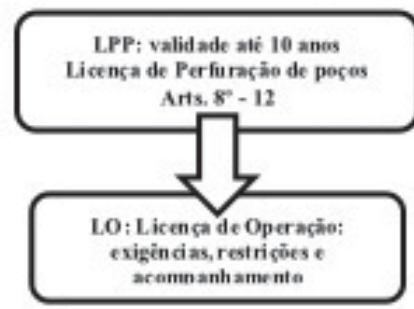

FCAFicha de Caracterizachio de Atividade: Empreendeder envia an IBAMA

IBAMA dass ifica em classe I. classe 2 ou classe 3 , de acerdo cam a nrofundid ade

Classe 1: exige-se EIARIMA Classe 2: exige-se EAP/RIAP Calsse 3; exige-se EAP

IBAMA emite TR-Terme de

Referéncia 15 dias úteis do protecele da FCA

Empreendedor encaminha

Terme de Requerimente de

Licenș de Op. com a TR

AP - Audiēnda Püblica (pode serna presencial)

IBAMA analis a contribuiçōes da AP esolicita eventuais esdaredimentes

Empreendedor presta esdarecimentos em at $\dot{\epsilon} 4$ meses da solicitar în

IBAMA pode soliditar estude preliminar de dispersio de poluentes

IBAMA poderí licendiar em blece (áreas poligonais) na Classe 1 (Art.10)

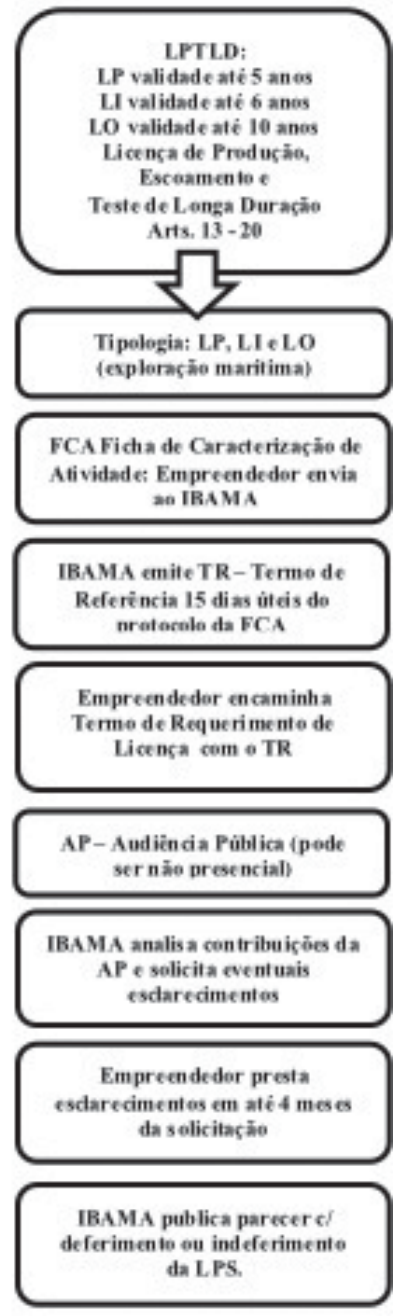

Figura 3: Espécies de Licenciamento Ambiental na Portaria MMA 422/2011

Fonte: Adaptada da Portaria MMA 422/2011 


\section{Zona do Pré-Sal Brasileiro: conceito e caracterização}

A zona do Pré-Sal (PALMA, 2011, p. 29) compreende as reservas de hidrocarbonetos de rochas calcárias localizadas abaixo das camadas de sal, possibilitando a descoberta de petróleo em faixas de 5.000 até 7.000 metros de profundidade abaixo do nível do mar; tal camada é apresentada em torno de $800 \mathrm{~km}$ de extensão por $200 \mathrm{~km}$ de largura, indo do litoral de Santa Catarina até o Espírito Santo.

Desde 1970, a Petrobras já investigava a existência de fontes petrolíferas na região, contudo a tecnologia ainda era incipiente para a prospecção que ultrapassa uma lâmina d'água superior a $2.000 \mathrm{~m}$, uma camada de sedimentos em torno de $1.000 \mathrm{~m}$ e uma terceira de aproximadamente 2.000m de sal, envolvendo as bacias de Santos, Campos e Espírito Santo e sinalizando eventual condição de país exportador ao Brasil.

Alguns campos de petróleo já foram explorados na região do Pré-Sal, dentre os quais: Tupi (reserva estimada entre 5 a 8 bilhões de barris) Guará, Bem-te-vi, Carioca, Júpiter e Iara. Entretanto, em rumo oposto à propalada autonomia econômica no cenário internacional, o governo brasileiro praticamente anulou o debate sobre a sustentabilidade e a promoção de riscos em tal atividade, além de mascarar o incentivo financeiro a uma matriz energética cara e altamente degradante, dado constatável historicamente dos danos oriundos da prospecção, do transporte, do armazenamento e da comercialização de tal modalidade combustível.

O frágil e açodado "debate", promovido pela Agência Nacional do Petróleo, Ministério das Minas e Energia, Ministério das Ciências e Tecnologia, Petrobras e demais atores interessados na execução do Projeto Pré-Sal, ignora o fato da inexistência de tecnologia suficiente para amenizar ou para até mesmo mensurar os riscos envolvidos (notadamente pela questão sísmica da área) e níveis de segurança desejáveis com uma coerência científica preventiva, notadamente na hipótese de acidente.

Diante da teoria do risco de desenvolvimento e, de maneira irresponsável, investe-se em um paradigma energético contraditório à sadia qualidade de vida, desrespeitando a ótica da variável ambiental e resumindo as externalidades de uma atividade impactante ao debate dos "di- 
videndos sociais" do petróleo e repartição de royalties, quando o cerne da questão deveria ser o princípio constitucional da variável ambiental, da prevenção e precaução e ausência de um debate intergeracional e de boa governança internacional, pois o Brasil será o primeiro a explorar a referida área e, no atual "estado da arte", qual a garantia da existência de tecnologia na hipótese de vazamento em região tão profunda?

Diante do cenário imposto pelas autoridades brasileiras, apresenta-se um perigoso e irreversível quadro de tolerância com a encampação de atividades sem a prévia noção dos efeitos e potenciais impactos à natureza e, principalmente, a negação à pesquisa e ao investimento nas fontes energéticas limpas, de menor custo e socialmente responsáveis.

A produção do petróleo oriundo da zona Pré-Sal, como toda e qualquer atitude causadora de externalidade negativa, deveria ser uma decisão aberta, democrática, tecnicamente ancorada em tecnologia suficiente e comprovadamente precisa para evitar e conter eventuais acidentes ocorridos, uma vez que o potencial de sinistralidade na prospecção, transporte e comercialização do petróleo e seus derivados é altíssimo e quase sempre de efeitos transfronteiriços, a exemplo do recente derramamento de óleo na Bacia de Campos, verificado em 7 de novembro de 2011, sob a responsabilidade das empresas Chevron e Petrobras, na qual estima-se o vazamento de 1.400 a 2.310 barris no campo de Frade, com extensão da mancha para160 $\mathrm{km}^{2}$, consoante a ANP, além do vazamento de gás da plataforma P-40, em Macaé, na mesma bacia fluminense. ${ }^{8}$

O uso de tecnologias na busca de fontes energéticas deve ser compatibilizado com a análise de um possível e exponencial acréscimo dos fatores de risco e afrouxamento das regras preventivas e precaucionais internas e internacionais, além de respeitar o princípio da proibição do retrocesso ecológico, diante do verdadeiro culto ao petróleo, promovido pelo governo brasileiro, desprezando o dado de que as somas vultosas de investimento na prospecção da região Pré-Sal poderiam ser direcionadas

8 Disponível em: <http://www.jornaldaciencia.org.br>. Acesso em: 28 nov. 2011; e Notícias da ANP. Disponível em: <http://www.anp.org.br>. Acesso em: 28 nov. 2011. 
para o combate às desigualdades sociais sem diminuir os níveis de qualidade de vida hoje existentes. ${ }^{9}$

Insiste-se no rumo do petróleo como se nenhuma outra fonte de energia limpa e renovável existisse e até o presente momento não foi divulgado estudo conclusivo sobre a concentração de $\mathrm{CO}^{2}$ e emissão efetuada com a exploração do Pré-Sal, apenas constando na página da Petrobras o quantitativo da emissão dos atuais empreendimentos, tentando justificar uma pretensa transparência na conduta ambiental e legitimar o uso da tecnologia poluente, inexistindo, de tal forma, preocupação com a transparência de dados e muito menos com o esclarecimento da população brasileira.

\section{Conclusões}

Atualmente, os problemas ambientais de segunda geração devem abrir espaço para a sustentabilidade forte, duradoura, principalmente nas hipóteses de riscos de grave dimensão, como na exploração do petróleo do Pré-Sal, em que a incerteza ainda domina o cenário científico ainda pressionado pela ingerência econômica.

A gestão da Zona Costeira e do Brasil e seu magnífico acervo marítimo dependem de um contínuo esforço de cooperação e planejamento preventivo e precaucional, no âmbito internacional, consoante às lições da nova hermenêutica do direito ambiental.

O Brasil, ao contrário das diretrizes internacionais de aproveitamento energético e redução da emissão de poluentes, insiste em investir em tecnologia pesada e suja com o fito de obter independência econômica utilizando o petróleo como matriz energética ultrapassada, altamente impactante, remontando aos primórdios do monopólio estatal e ao início da prospecção, calcado na exclusiva preocupação da partilha dos royalties.

A necessidade de investimentos para erradicação da miséria e das desigualdades regionais é imperiosa; contudo, o preço a pagar consiste na

9 Notícias sobre o Encontro de Meio Ambiente em são Paulo. Disponível em: <www. seesp.org.br>. Acesso em: 23 out. 2011. 
degradação do meio ambiente sem a menor garantia de critérios científicos claros, abertos ao conhecimento popular e franqueando um indispensável debate?

Não se pretende divulgar a eternização do debate científico e dos pilares da tecnologia empregada no Pré-Sal; apenas alerta-se para o apressado processo de licenciamento, imposto pela recente Portaria MMA n. 422/2011 e os possíveis vícios de inconstitucionalidade do seu fluxo e, de igual forma, lamenta-se a ausência de debates com a sociedade para a discussão de fontes alternativas de energia, implicando na supressão constitucional da participação popular na condução dos processos decisórios sobre o meio ambiente e na inexistência de uma verdadeira política energética brasileira.

Qualquer investimento em técnica impactante deve estar ancorado em sólidas e exaustivas bases científicas, o que não se pode afirmar de uma atividade realizada pela primeira vez, em profundidade tão ampla, aliada aos inúmeros exemplos históricos de elevação dos índices de poluição e catástrofes/acidentes locais e mundiais no lamentável catálogo da degradação do meio ambiente.

Enfim, as gerações do futuro devem sofrer com decisões das quais não participaram e tomadas em torno de critérios não divulgados e sem a obediência aos ditames constitucionais?

Qual o preço do fomento das políticas de combate às desigualdades regionais e sociais?

\section{Referências}

AMBIENTE BRASIL. [2011]. Disponível em: <www.ambientebrasil. com.br>. Acesso em: 23 out. 2011.

BECK, Ulrich. Sociedade de risco: rumo a uma outra modernidade. São Paulo: 34, 2010.

DERANI, Cristiane. Direito ambiental econômico. São Paulo: Saraiva, 2008. 
CANOTILHO, José Joaquim Gomes; LEITE, José Rubens Morato (Org.). Direito constitucional ambiental brasileiro. São Paulo: Saraiva, 2011.

LEITE, José Rubens Morato. Dano ambiental: do individual ao coletivo extrapatrimonial. São Paulo: Revista dos Tribunais, 2010.

LOPEZ, Teresa Ancona. Princípio da precaução e evolução da responsabilidade civil. São Paulo: Quartier Latin, 2010.

PALMA, Carol Manzoli. Petróleo: exploração, produção e transporte sob a óptica do Direito Ambiental. Campinas: Millennium, 2011.

PRUDENTE, Antônio Souza. Hidrelétrica Belo Monte: manifesta agressão ao princípio da proibição do retrocesso ecológico. Revista CEJ, Brasília, Ano XIV, n. 51, p. 33-40, out./dez. 2010.

RADIO LAGES. Julgamento do acidente do navio Prestige começa hoje na Galiza. 16 de outubro de 2012. Disponível em: <http://www. radiolajes.pt/julgamento-do-acidente-do-navio-prestige-comeca-hoje-nagaliza>. Acesso em: $1^{\mathrm{o}}$ nov. 2012.

REVISTA VEJA [on-line]. BP: Sequência de falhas causou vazamento de petróleo. Agosto de 2010. Disponível em: <http://veja.abril.com.br/ noticia/internacional/sequencia-de-falhas-causou-vazamento-de-petroleodiz-bp>. Acesso em: $1^{\mathrm{o}}$ nov. 2012.

WINTER, Gerd. Desenvolvimento sustentável, OGM e responsabilidade civil na União Européia. Campinas: Millennium, 2009.

POPPER, Karl. A lógica das ciências sociais. Tradução de Estevão de Rezende Martins. 3. ed. Rio de Janeiro: Tempo Brasileiro, 2004.

. O mito do contexto: em defesa da ciência e da racionalidade.

Lisboa: Edições 70, 2009. 